\title{
Get A Life: Fast and Furious Cataloging for the Overworked and Underutilized Teacher Librarian
}

\author{
Dianne McKenzie \\ PT Teacher Librarian \\ Australian International School Hong Kong \\ $3 A$ Norfolk $R d$, \\ Kowloon Tong. Kowloon \\ Hong Kong \\ dmckenzie@aishk.edu.hk
}

\begin{abstract}
This workshop and paper is intended to give participants an idea of the types of services currently being offered. The products and services listed here are done so for the participants' information and ease of follow up in collecting information about what their needs are. The author has no links with any of these companies and by their inclusion is not recommending any of them in particular. By the dynamic nature of the Internet, web sites will change and even though the author has checked the websites listed before publication, there is no guarantee they will be the same when you visit them.
\end{abstract}

Cataloging is one of those chores of the library that needs to be done, is never ending, time consuming and at all times needs to be accurate. This creates a dilemma for the school librarians who need to be a jack of trades, and a master of all, in most cases with little or no trained support. It is a vicious cycle - they need to expand their libraries collection through purchasing the new resources but have little time to get it to the point so the end users can access it because they need to catalog it - and who has time for that?

There have been considerable developments over the years to help school librarians reduce the amount of time they need to do original cataloging - SCIS in Australia, OCLC in the US and other countries and many counties in the US have their own OPACS accessible by all the district schools. These services are liberating for those schools who have a community environment such a county or district which is supportive or even a total government policy which makes these services free. What about schools who do not have these support mechanisms in place - the ever expanding number of international schools who work in isolation in countries far away from their home country who have resources from many parts of the world but who do not receive any aid from any government? What about schools in lands that do not have the sophisticated OPACs available in their countries? What about the schools that simply cannot afford to access these ready to download records? With the current globalization of information and technology through the internet there is a vast opportunity for use of and collaboration with sophisticated OPAC services for a low price, or even free, to liberate the school librarian from the cataloging burden, so they may utilize their time more effectively in service to their clients in supplying and making sense of information. 
This workshop addresses a number of alternatives that School Librarians can use to reduce the time and money they spend on original cataloging whilst maintaining the integrity of the cataloging standards. These include:

- Original cataloging

- Copy cataloging

- Cataloging from CD ROM records

- Cataloging databases

- Z39.5 Software available.

\section{Original Cataloging}

The librarian performs original cataloging by inputting a new master record, cataloged according to AACR2 $1988 \mathrm{rev}$. and current cataloging practice.

This is slow and sometimes inaccurate if you haven't spent years training to be an original cataloger. In my experience in schools, items that need to be original cataloged are left to when there is enough time to do it - and eventually get done when the need arises for those resources. There are so many different types of formats of resources with different requirements that the decision as to what classification number and subject headings sometimes takes more time than it is worth for the non highly trained cataloger. The other important aspect about being a school librarian is that we have other things to do which do not need to include original cataloging. A reflection on the time and resources required in original cataloging is reflected in the costs charged by cataloging companies - if it was an easy job, it would be free.

However original cataloging is sometimes required when the resource can be found no where else. There are a few online helpers to assist in this task, below is one of them

Marc 21 Concise Format for Bibliographic data (Library of Congress)

http://lcweb.loc.gov/marc/bibliographic/ecbdhome.html

A brief description of the field and what should go in there and the appropriate punctuations.

The Head Librarian of Hong Kong Institute of Education suggested that no more than $5 \%$ of records need to be original cataloged due to the number of services available today.

\section{Copy Cataloging}

You perform copy cataloging by modifying an existing record. In the simplest terms this means finding a record that you need, and copying and pasting the information into your OPAC in the relevant places.

\section{Advantages}

The records have usually been done by 'professionals' and will be accurate. All the information you need will be there, and you will see where the information needs to go. If you physically visit the OPAC of large libraries such as LC, The British Library and university libraries and copy and paste the records directly from their OPAC, this method is free. This method is suitable for libraries which do not catalog a lot of resources, and which cannot afford to subscribe to a large database or service. 


\section{Problems}

The time to find the Library OPAC with the record on it. It can take the same amount of time as doing the original cataloging to find the resource and you can only search on one OPAC at a time - unless a few of them are linked for a common reason. The need to ensure the record you are copying is actually the resource you want cataloged. There is also the need to modify the record to suit local requirements.

Some of the Library OPACs we have found useful to copy records from are:

National Library of Australia

http://webpac.nla.gov.au/webclientmain.html

\section{Library of Congress}

http://catalog.loc.gov/

British Library Public catalog

http://blpc.bl.uk/

A list of library catalogs from the USA

http://www.sunlink.ucf.edu/faq/marc_download/default.html

Suffolk County Library catalog

www.suffolk.lib.ny.us

For specific local resources, visit the national libraries and universities of the language/ resource that you need the record for.

\section{ROM Catalog Databases}

This service is one where thousands and even millions of MARC records are downloaded onto a CD ROM, the school buys the CD ROMs and searches the database on the CD ROM for the required records, then downloads the information from the CD ROM.

\section{Advantages}

These are worthwhile for schools who do not have any reliable online access.

\section{Problems}

They are being superceded by the Internet. They are limited to what is on the disc and can be outdated quickly, hence payment for regular updates are required. Require a lot of disc swapping if there is not the possibility of multiple CD loading.

Laserquest is one of the options available, they boast 9.8 million records, they also mention that if a library acquires more than 2500 new resources a year, then it will pay for itself in time saved. Further information on this product can be found at :

GRC International ( 5 million records)

http://www.grci.com/whatwedo/library/lquest/index.htm

Fastcat is another CD ROM catalog developed for Schools (1 million records)

http://www.wln.com/products/cd-roms/fastcat.htm 
Alliance Plus is another product available for cataloging from CD ROM

1.8 million records with $2-4$ updates per year. There are a couple of other requirements to be met. about US $\$ 449$. More information can be found at

http://www.fsc.follett.com/products/allianceplusonline/sellsheet.pdf

\section{Online Catalog Databases}

These are usually a huge database of records that you can search, access and download records into your system for a fee - sometimes it is just a flat fee per annum, or it could also involve a membership fee and then a charge for every record searched and downloaded, depending on where they get their records from, for the standard of cataloging can vary. Some use a credit system for those libraries prepared to share their records to reduce their download fee, and some hire professional catalogers to input just for their database.

\section{Advantages}

The volume of records to search in some of the databases is huge. The service is quick, and usually supported

Use of the internet

\section{Problems}

The cost is an annual fee and can be quite high. The rate at which items are cataloged can sometimes be delayed due to the volume. Schools may not need the volume of records to search through and may not get cost effectiveness.

Some of the catalog databases are:

Follett's Alliance Plus Online (3.9 million records) \$249 US Dollars+

http://www.fsc.follett.com/products/allianceplusonline/sellsheet.pdf

Schools Catalogue Information Service (SCIS)

Over 1200 downloads per year is $\$ 900$ AUD. Contains over 700,000 records.

Mainly Australian in origin. http://www.curriculum.edu.au/scis/

Precision One by Brodart.com

2 million records http://www.brodart.com

IT's Marc

US based online based, 15 million records

http://www.tlcdelivers.com/tlccarl/products/cataloging/itsmarcoffer.asp

OCLC Catexpress - access to 47 million records

membership fee plus download per record fee

demo tutorial at http://www.purl.org/oclc/catxtutorial

http://www.oclc.org/oclc/cataloging/catexpress/CatExpress.pdf

MarciveWeb Select

http://www.marcive.com/HOMEPAGE/web6.htm

offers a 30 day free trial 
AV Access Plus from professional Media Services Corp.

Specifically for AV materials 500,000 records

Free trial version

http://www.promedia.com/

Sagebrush

Offers a total package for system operation as well as databases.

http://www.sagebrushcorp.com/dataservices/databases.cfm

\section{Z39.50 Software}

Z39.50 is a protocol that allows downloading of marc records from one library system to another. It allows users to search one or more collections over the Internet simultaneously, searching by author, title, subject, ISBN, ISSN, LCCN etc. and then downloading the MARC records required into the searchers system. It is the way of the future in copy cataloging and has shown rapid growth since its inception in 1988.

\section{Advantages}

A one off fee for the software - no further budgeting required. Huge number of records available, and each record is a free download. Through a selection of target servers, the searcher can narrow the type of library searched, making the search more specific. The records gained are usually recorded by professionals.

\section{Problems}

Reliance on the Internet.

There is the possibility of having the Z39.50 software in its raw form from various places http://www.loc.gov/z3950/agency/resources/software.html

but it is probably easier to buy the interface software from a company who has developed a user friendly version. A couple of alternatives are:

eZcat and eZcat pro from Book Systems

http://www. booksys.com/products/eZcat/eZcat.shtml

they offer a 15 day free trial, a one off purchase price and then download as many records as you need as long as you own the software. $\$ 595$ US / \$995 US site as a one off payment. You can pay $\$ 100$ US a year for support and updates. eZcat is MAC and PC compatible.

Bookwhere? 2000 from Follett

offer a 45 day free trial and costs $\$ 395$ US

http://www.fsc.follett.com/products/bookwhere2000/index.cfm

A list of libraries which are $Z 39.5$ servers can be found at http://www.sunlink. ucf.edu/faq/marc download/default.html

This is a list complied by school librarians who use a Z39.5 interface and receive the highest amount of hits from these libraries - also included special libraries. US based.

A close to complete list of all international targets can be found at http://www.indexdata.dk/targettest/ 


\section{Conclusion}

From the vast array of possibilities in automated cataloging, there really is no reason for school librarians to be doing more than $5 \%$ original cataloging. They have the opportunity to use free and low cost resources to help them in this onerous task and to keep their records as accurate as possible. With the advent of the Internet, the world has become smaller, our catalogs can be shared and our libraries have the potential to become worldly places and our students and staff will benefit from these opportunities which free us up for more important work - that of teaching. 